\section{BRAZIULIAN JOURNAL}

OF MEDICAL AND BIOLOGICAL RESFARCH

www.bjournal.com.br
ISSN 0100-879X

Volume 43 (9) 812-913 September 2010

BIOMEDICAL SCIENCES

AND

CLINICAL INVESTIGATION

Braz J Med Biol Res, September 2010, Volume 43(9) 869-873

doi: 10.1590/S0100-879X2010007500075

Effects of reversible inactivation of the dorsomedial hypothalamus on panic- and anxiety-related responses in rats

J.O.G. Nascimento, H. Zangrossi Jr. and M.B. Viana

The Brazilian Journal of Medical and Biological Research is partially financed by
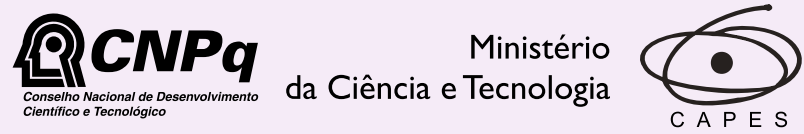

Ministério da Educação

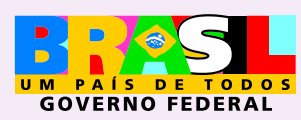

DFAPESP

Institutional Sponsors
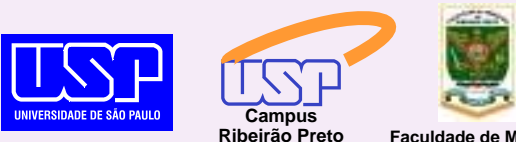

Ф SHIMADZU

GE Healthcare
Hotsite of proteomics metabolomics developped by: 


\title{
Effects of reversible inactivation of the dorsomedial hypothalamus on panic- and anxiety-related responses in rats
}

\author{
J.O.G. Nascimento ${ }^{1}$, H. Zangrossi Jr. ${ }^{2}$ and M.B. Viana ${ }^{3}$ \\ ${ }^{1}$ Departamento de Psiquiatria, Universidade Federal de São Paulo, São Paulo, SP, Brasil \\ ${ }^{2}$ Departamento de Farmacologia, Faculdade de Medicina de Ribeirao Preto, \\ Universidade de São Paulo, Ribeirão Preto, SP, Brasil \\ ${ }^{3}$ Departamento de Biociências, Universidade Federal de São Paulo, Santos, SP, Brasil
}

\begin{abstract}
The medial hypothalamus is part of a neurobiological substrate controlling defensive behavior. It has been shown that a hypothalamic nucleus, the dorsomedial hypothalamus $(\mathrm{DMH})$, is involved in the regulation of escape, a defensive behavior related to panic attacks. The role played by the $\mathrm{DMH}$ in the organization of conditioned fear responses, however, is less clear. In the present study, we investigated the effects of reversible inactivation of the $\mathrm{DMH}$ with the $\mathrm{GABA}_{\mathrm{A}}$ agonist muscimol on inhibitory avoidance acquisition and escape expression by male Wistar rats (approximately $280 \mathrm{~g}$ in weight) tested in the elevated T-maze (ETM). In the ETM, inhibitory avoidance, a conditioned defensive response, has been associated with generalized anxiety disorder. Results showed that intra-DMH administration of the $\mathrm{GABA}_{\mathrm{A}}$ receptor agonist muscimol inhibited escape performance, suggesting an antipanic-like effect $(P<0.05)$, without changing inhibitory avoidance acquisition. Although a higher dose of muscimol $(1.0 \mathrm{nmol} / 0.2 \mu \mathrm{L} ; \mathrm{N}=7)$ also altered locomotor activity in an open field when compared to control animals $(0.2 \mu \mathrm{L}$ saline; $N=13)(P<0.05)$, the lower dose $(0.5 \mathrm{nmol} / 0.2 \mu \mathrm{L} ; \mathrm{N}=12)$ of muscimol did not cause any motor impairment. These data corroborate previous evidence suggesting that the $\mathrm{DMH}$ is specifically involved in the modulation of escape. Dysfunction of this regulatory mechanism may be relevant in the genesis/maintenance of panic disorder.
\end{abstract}

Key words: Muscimol; Generalized anxiety disorder; Panic disorder; Dorsomedial hypothalamus; Elevated T-maze

\section{Introduction}

The medial hypothalamus has been implicated in the regulation of a series of different behavioral and physiological functions, such as food ingestion and metabolism, reproduction, and defense (1). This region contains a number of anatomically and functionally well-defined cell groups (1), such as the dorsomedial hypothalamus (DMH), the anterior hypothalamic nucleus, the dorsomedial part of the ventromedial hypothalamus (VMHdm) and the dorsal premammillary nucleus. These nuclei are interconnected and, regarding defensive reactions, seem to be especially involved in the integration of innate responses to environmental threats (1-4). In fact, it has been shown that the electrical stimulation of this region induces unconditioned escape behavior and autonomic arousal resembling those presented by animals when facing natural threats $(5,6)$. Intramedial hypothalamus administration of glutamate agonists $(2,7)$ and of GABA antagonists $(3,8,9)$ also evokes a similar defense pattern. This last observation suggests that GABAergic mechanisms exert a tonic inhibition on this neural substrate of defense.

It is interesting to point out that, based on the ethopharmacological analysis of the rodent defensive repertoire, escape behavior has been associated with fear $(10,11)$, and dysfunction of the brain circuitry controlling this behavior has been related to panic disorder $(10,12)$. Thus, altogether, previous studies suggest that the medial hypothalamus plays a relevant role not only in the regulation of escape behavior but also in the pathophysiology of panic disorder $(3,13)$. The role of the region in the regulation of conditioned defense reactions, however, is less clear. Given the importance of the medial hypothalamus in defense, a full understanding of the extent to which this region also

Correspondence: M.B. Viana, Departamento de Biociências, Universidade Federal de São Paulo, Campus Baixada Santista, 11060-001 Santos, SP, Brasil. E-mail: mviana@unifesp.br

Received April 3, 2010. Accepted July 23, 2010. Available online August 6, 2010. Published September 13, 2010. 
integrates conditioned fear is of relevance.

In the present study, we compared the relationship of a specific hypothalamic nucleus, the $\mathrm{DMH}$, with escape and conditioned defense reactions in the same animal. For this purpose, male Wistar rats were injected intra-DMH with the $\mathrm{GABA}_{\mathrm{A}}$ receptor agonist muscimol and tested in the elevated T-maze (ETM). Muscimol was used to reversibly inactivate the nucleus. In the ETM, escape behavior is induced by an ethologically relevant threatening stimulus, i.e., the exposure of rats to an open and elevated space (14-16). Besides escape, the model also allows the measurement of inhibitory avoidance (14), a conditioned defense response. The pharmacological validation of the ETM has shown that compounds representative of three classes of anxiolytics - namely the agonist of benzodiazepine receptors diazepam, the serotonin (5-HT) 1A agonist buspirone, and the nonselective $5-\mathrm{HT}_{2}$ antagonist ritanserin - selectively impair inhibitory avoidance while leaving one-way escape unchanged (14). These results are compatible with the view that inhibitory avoidance relates to generalized anxiety. In contrast, the escape task is impaired by chronic, but not acute administration of imipramine (15), clomipramine and fluoxetine (16), drugs that are used to treat panic. As a result, one-way escape in the ETM has been used as an animal model of panic disorder.

In order to avoid confounding results due to drug effects on locomotor activity, after tests in the ETM, animals were also evaluated in an open field.

\section{Subjects and Methods}

\section{Subjects}

Twenty-nine male Wistar rats (Federal University of São Paulo, CEDEME, Brazil) weighing approximately $280 \mathrm{~g}$ at the beginning of the experiment were housed in groups of 5-6 per cage. After surgery, animals were housed in pairs in Plexiglas-walled cages until testing. Room temperature was controlled $\left(22 \pm 1^{\circ} \mathrm{C}\right)$ and a light-dark cycle was maintained on a 12-h on-off cycle (lights on from 7:00 to 19:00 h). Food and water were available throughout the experiments. The study was performed in compliance with the recommendations of the SBNeC (Brazilian Society of Neuroscience and Behavior), which are based on the US National Institutes of Health Guide for Care and Use of Laboratory Animals.

\section{Apparatus}

The elevated T-maze was made of wood and had 3 arms of equal dimensions $(50 \times 12 \mathrm{~cm})$. One of the arms was enclosed by $40-\mathrm{cm}$ high walls and was oriented perpendicularly to two opposite open arms. The whole apparatus was elevated $50 \mathrm{~cm}$ above the floor. To avoid falls, the open arms were surrounded by a 1-cm high Plexiglas rim.

The open field test was performed in a wooden square arena $(60 \times 60 \mathrm{~cm})$ with $30-\mathrm{cm}$ high walls. Luminosity at the level of the maze arms or the open field center was 60 lux.

\section{Drugs}

Muscimol (0.5 and $1.0 \mathrm{nmol}$; Sigma, USA) was dissolved in sterile saline. Control animals received sterile saline. Drug and saline were administered in a volume of $0.2 \mu \mathrm{L}$.

\section{Surgery}

Rats were anesthetized with an intraperitoneal (ip) injection of ketamine hydrochloride ( $80 \mathrm{mg} / \mathrm{kg}$; Agribrands, Brazil) and xylazine (10 mg/kg; Agribrands) and fixed to a stereotaxic frame (Insight, Brazil). Before the implant of a stainless steel guide cannula into the $\mathrm{DMH}$, the animals received local anesthesia with $2 \%$ lidocaine with a vasoconstrictor (Harvey, Brazil). The cannula (0.6-mm outer diameter and $0.4-\mathrm{mm}$ inner diameter) was inserted into the right side of the brain through a hole drilled in the skull above the hypothalamic nucleus, following the coordinates from the atlas of Paxinos and Watson (17): $A P=-3.1 \mathrm{~mm}$ from Bregma, $\mathrm{ML}=+0.6 \mathrm{~mm}$, and $\mathrm{DV}=-7.2$. Guide cannulas were attached by means of acrylic resin and a stainless steel screw. Stylets with the same length as the guide cannula were introduced inside them to avoid obstruction. To prevent infections, at the end of surgery, all animals were injected intramuscularly with $0.2 \mathrm{~mL}$ of a pentabiotic preparation (Pentabiótico Veterinário Pequeno Porte; Forte Dodge, Brazil) and with the anti-inflammatory Banamine (1 $\mathrm{mL} / \mathrm{kg}$, sc; Fort Dodge).

\section{Microinjections}

For drug injection, needles (0.3-mm outer diameter) were introduced through the guide cannula until their tip was $2 \mathrm{~mm}$ below the cannula end. Muscimol and saline were injected over a period of $120 \mathrm{~s}$ using $5-\mu \mathrm{L}$ microsyringes (Hamilton 701-RN, USA) attached to a microinfusion pump (Insight). The displacement of an air bubble inside the polyethylene catheter connecting the syringe needle to the intracerebral needle was used to monitor the microinjection. The intracerebral needles were removed $60 \mathrm{~s}$ after the end of injection.

\section{Procedure}

Five days after surgery, the animals were exposed to one of the open arms of the ETM for 30 min as described by Sena et al. (18). It has been shown that pre-exposure renders the escape task more sensitive to the effects of antipanic drugs because it shortens the latencies of withdrawal from the open arm during the test (18). On the next day, rats were injected $(0.2 \mu \mathrm{L}, 2 \mathrm{~min})$ with muscimol $(0.5$ and $1.0 \mathrm{nmol}$ ) or saline. Ten minutes later, ETM-inhibitory avoidance was measured by recording the time taken by the rats to withdraw from the enclosed arm of the maze in three consecutive trials at 30-s intervals (baseline, avoidance 1 and 2). Following avoidance training (30 s), each animal 
was placed at the end of the same open arm as used in the pre-exposure session and the time taken to leave this arm was recorded in three consecutive trials (escape 1 to 3 ), again with 30 -s inter-trial intervals. Immediately after the tests in the ETM, animals were placed in the center of the open field and allowed to freely explore for $5 \mathrm{~min}$.

\section{Histology}

After the experiments, animals were sacrificed under deep urethane anesthesia. Their brains were perfused through the heart with saline followed by $10 \%$ formalin, before being removed and fixed in $10 \%$ formalin. Frozen sections of $55 \mu \mathrm{m}$ were cut with a microtome (Leica, Germany) in order to locate the site of drug injections (17).

\section{Statistical analysis}

Avoidance and escape data were submitted to repeated measures analysis of variance (ANOVA), with treatment as the independent factor and trials (baseline, avoidance 1 and 2 or escape 1, 2, and 3 latencies) as the dependent factor. When appropriate, group comparisons were made by the Tukey test. Locomotor activity data in the open field were analyzed by one-way ANOVA followed by the Tukey test. A value of $P \leq 0.05$ was considered to be significant.

\section{Results}

Figure 1 (upper panel, left side) shows intra-DMH injection of muscimol on ETM-inhibitory avoidance acquisition.
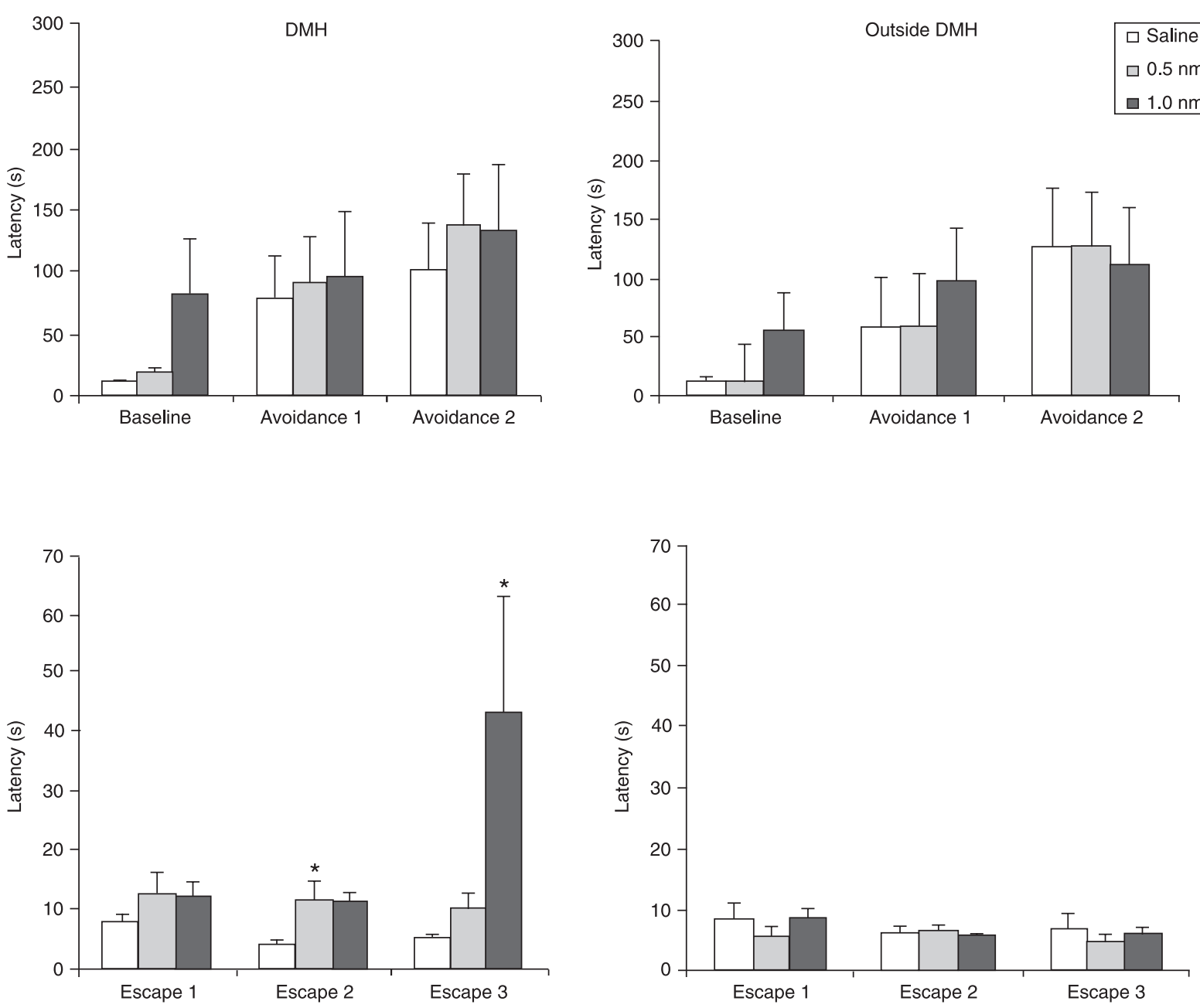

Figure 1. Effects (mean + SEM) of intra-dorsomedial hypothalamus (DMH) muscimol (0.5 and $1.0 \mathrm{nmol} / 0.2 \mu \mathrm{L}$; left side) on inhibitory avoidance (upper panel) and escape (lower panel) latencies measured in the elevated T-maze (left side). The effects of injections outside the nucleus are represented on the right side of the figure. The latencies to leave the enclosed arm (baseline, avoidance 1 and avoidance 2) or one of the open arms (escape 1-3) were measured sequentially at 30-s intervals beginning 10 min after intra$\mathrm{DMH}$ injection of either drug or saline. $\mathrm{N}=13$ (saline), $12(0.5 \mathrm{nmol})$ and $7(1.0 \mathrm{nmol})$. ${ }^{*} \mathrm{P}<0.05$ compared to control in the same trial (ANOVA followed by the Tukey post hoc test). 
Repeated measures ANOVA showed a significant effect of trials $[F(2,58)=6.60 ; P=0.003]$, but not of treatment $[F(2,29)=0.482 ; P=0.623]$ or of treatment by trial interaction $[F(4,58)=0.397 ; P=0.810]$. In a similar way, injections of muscimol outside the $\mathrm{DMH}$ did not alter inhibitory avoidance in the ETM (Figure 1, upper panel, right side).

Figure 1 (lower panel, left side) shows intra-DMH injection of muscimol on ETM escape. Repeated measures ANOVA showed a significant effect of trials $[F(2,58)=4.659$; $\mathrm{P}=0.013]$, treatment $[\mathrm{F}(2,29)=5.379 ; \mathrm{P}=0.010]$ and treatment by trial interaction $[F(4,58)=4.855 ; P=0.002]$. The Tukey post hoc test showed that animals treated with $0.5 \mathrm{nmol}$ muscimol were significantly different from the control group in escape 2 and that animals treated with 1.0 $\mathrm{nmol}$ muscimol were significantly different from the control group in escape $3(P<0.05)$. On the other hand, escape measurements were not altered by injections of muscimol outside the DMH (Figure 1, lower panel, right side).

As shown in Figure 2 (left side), both the number of crossings and the number of rearings in the open field were significantly altered by the highest dose of muscimol $(1.0 \mathrm{nmol})$ administered intra-DMH $(\mathrm{P}<0.05)$. In contrast, neither the number of crossings nor the number of rearings in the open field were significantly altered by injections of muscimol outside the DMH (Figure 2, right side).

\section{Discussion}

The present results showed that the temporary inactivation of the $\mathrm{DMH}$ by local injection of the $\mathrm{GABA}_{A}$ agonist muscimol selectively impaired escape behavior in the ETM, a panicolytic effect. Although the highest dose of muscimol administered $(1.0 \mathrm{nmol})$ also altered locomotor activity in the open field, the lower dose $(0.5 \mathrm{nmol})$ did not cause any motor impairment. The decrease in locomotor activity was probably also responsible for the increase in baseline latencies observed after intra-DMH treatment with $1 \mathrm{nmol}$ muscimol (Figure 1, upper panel, left side). In fact, baseline latency in the ETM is used as an index of motor activity and not of fear/anxiety (15). Furthermore, the analysis of animals with cannula placement outside the $\mathrm{DMH}$ did not show any significant results in ETM avoidance or escape measurements (Figure 1, right side), confirming that the significant results observed were in fact due to the reversible inactivation of this hypothalamic nucleus.

The effect of DMH inactivation on escape expression corroborates previous reports. In fact, it has been shown that escape is evoked after chemical stimulation of the medial hypothalamus with glutamate agonists $(2,7)$. Similar observations have also been reported after local administration of GABA antagonists into the region (8-9). Furthermore, the injection of GABA/BZD agonists into the medial hypothalamus seems to modulate the aversive consequences of the electrical or chemical stimulation, raising the aversive threshold necessary to induce escape responses $(2,9)$. In the present study, the relationship between a specific nucleus of the medial hypothalamus, the $\mathrm{DMH}$, and escape was demonstrable when this behavior was evoked by an ethologically relevant threatening stimulus, i.e., exposure to an open and elevated space. As previously mentioned, dysfunction of the brain circuitry controlling escape has been related to panic disorder $(10,12)$. In this regard, it is worth mentioning that impairment of the GABAergic function of the $\mathrm{DMH}$ by chronic inhibition of the GABA synthesis inhibitor L-allylglycine (L-AG) induced robust panic-like responses in rats (3) that were prevented by administration of the benzodiazepine alprazolam and LY354740, a potent group II metabotropic glutamate receptor agonist (3). Thus, it seems that the $\mathrm{DMH}$ is, in fact, an important neurobiological substrate of the medial hypothalamic zone implicated in the pathophysiology of panic disorder.

On the other hand, intra-DMH administration of mus-
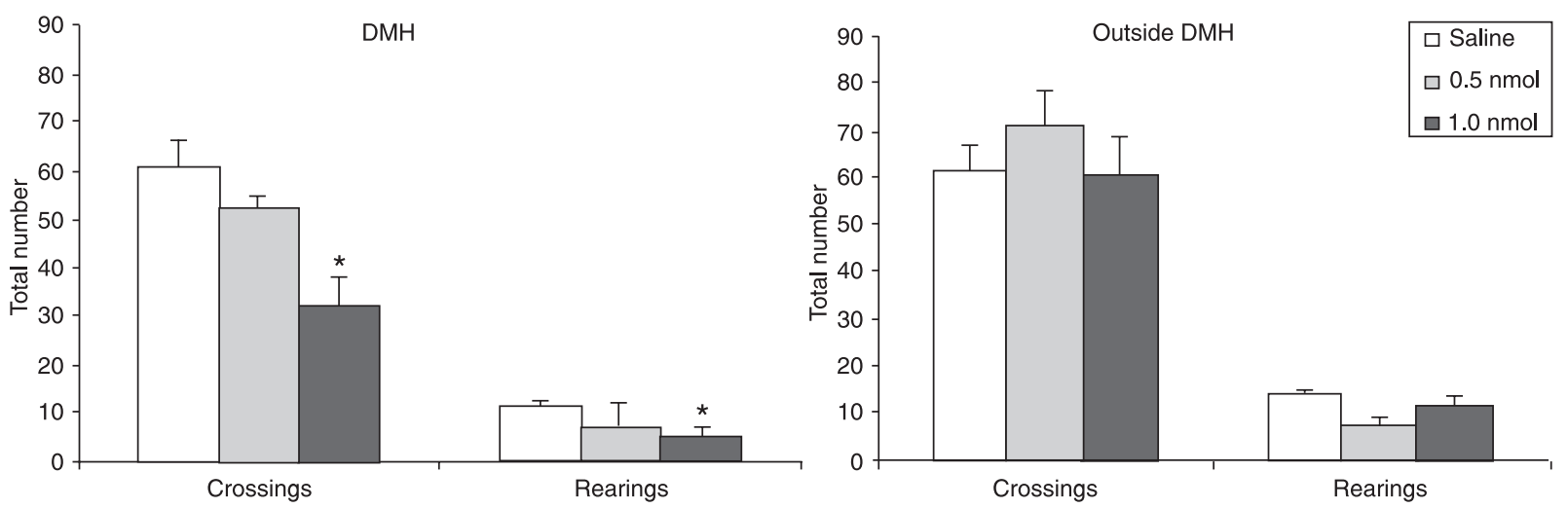

Figure 2. Effects (mean + SEM) of intra-dorsomedial hypothalamus (DMH) muscimol $(0.5$ and $1.0 \mathrm{nmol} / 0.2 \mu \mathrm{L})$ on the total number of crossings and rearings in an open field. The effects of injections outside the nucleus are represented on the right side of the figure. Measurements were made immediately after tests in the elevated T-maze. ${ }^{*} \mathrm{P}<0.05$ compared to control (ANOVA followed by the Tukey post hoc test). For additional information, see Figure 1. 
cimol did not change ETM avoidance measurements, a conditioned anxiety response. This effect corroborates what has been shown by Santos and co-workers (4) with the fearpotentiated startle response to light, also a conditioned fear reaction. In this particular study (4), both muscimol and the glutamic acid decarboxylase inhibitor semicarbazide were without effect when administered intra-DMH.

The results observed with the DMH are very similar to those obtained with another neuroanatomic region implicated in defense, i.e., the dorsal periaqueductal gray (dPAG). When administered intra-dPAG, muscimol also impaired escape, without altering ETM-inhibitory avoidance (19). In fact, the similarities of the role played by the medial hypothalamus and the dPAG in the modulation of defense were previously pointed out by Schmitt et al. (8), who showed that both intra-dPAG and intramedial hypothalamus administrations of SR 95103, a GABA-A receptor antagonist, produced a dose-dependent behavioral activation together with jumps. In contrast, the present results do not agree with those observed with another hypothalamic nucleus, the VMHdm (20). Previous observations have

\section{References}

1. Canteras NS. The medial hypothalamic defensive system: hodological organization and functional implications. Pharmacol Biochem Behav 2002; 71: 481-491.

2. Silveira MC, Graeff FG. Defense reaction elicited by microinjection of kainic acid into the medial hypothalamus of the rat: antagonism by a GABAA receptor agonist. Behav Neural Biol 1992; 57: 226-232.

3. Shekhar A, Keim SR. The circumventricular organs form a potential neural pathway for lactate sensitivity: implications for panic disorder. J Neurosci 1997; 17: 9726-9735.

4. Santos JM, Macedo CE, Brandao ML. Gabaergic mechanisms of hypothalamic nuclei in the expression of conditioned fear. Neurobiol Learn Mem 2008; 90: 560-568.

5. Hess WR, Brugger M. [Das subkortikale Zentrum der affektiven abwehrreacktion]. Helv Physiol Pharmacol Acta 1943; 1: $33-52$.

6. Fernandez de Molina A., Hunsperger RW. Organization of the subcortical system governing defence and flight reactions in the cat. J Physiol 1962; 160: 200-213.

7. Bailey TW, Dimicco JA. Chemical stimulation of the dorsomedial hypothalamus elevates plasma ACTH in conscious rats. Am J Physiol Regul Integr Comp Physiol 2001; 280: R8-R15.

8. Schmitt P, Di Scala G, Brandao ML, Karli P. Behavioral effects of microinjections of SR 95103, a new GABA-A antagonist, into the medial hypothalamus or the mesencephalic central gray. Eur J Pharmacol 1985; 117: 149-158.

9. Soltis RP, Dimicco JA. GABAA and excitatory amino acid receptors in dorsomedial hypothalamus and heart rate in rats. Am J Physiol 1991; 260: R13-R20.

10. Blanchard DC, Griebel G, Blanchard RJ. Mouse defensive behaviors: pharmacological and behavioral assays for anxiety and panic. Neurosci Biobehav Rev 2001; 25: 205-218. shown that muscimol inhibits both ETM-inhibitory avoidance and escape when administered intra-VMHdm. Thus, on the basis of these results, it seems possible that different medial hypothalamic nuclei play distinct roles in the modulation of fear/anxiety responses. While most caudal nuclei of the medial hypothalamus seem to modulate panic-related responses, such as escape, more rostral nuclei, such as the VMHdm, also mediate conditioned fear. Nevertheless, further work needs to be done to understand how these systems are possibly interrelated.

In conclusion, the results of the present study suggest that inactivation of the $\mathrm{DMH}$ by muscimol selectively alters escape, a defensive response related to panic. Dysfunction of this regulatory mechanism may be of relevance in the genesis/maintenance of panic disorder.

\section{Acknowledgments}

The authors thank FAPESP and CNPq for financial support. J.G.O. Nascimento was the recipient of a fellowship from CAPES.

11. Graeff FG. Serotonin, the periaqueductal gray and panic. Neurosci Biobehav Rev 2004; 28: 239-259.

12. McNaughton N, Corr PJ. A two-dimensional neuropsychology of defense: fear/anxiety and defensive distance. Neurosci Biobehav Rev 2004; 28: 285-305.

13. Shekhar A, Keim SR. LY354740, a potent group II metabotropic glutamate receptor agonist prevents lactateinduced panic-like response in panic-prone rats. Neuropharmacology 2000; 39: 1139-1146.

14. Viana MB, Tomaz C, Graeff FG. The elevated T-maze: a new animal model of anxiety and memory. Pharmacol Biochem Behav 1994; 49: 549-554.

15. Teixeira RC, Zangrossi H, Graeff FG. Behavioral effects of acute and chronic imipramine in the elevated T-maze model of anxiety. Pharmacol Biochem Behav 2000; 65: 571-576.

16. Poltronieri SC, Zangrossi H Jr, de Barros V. Antipanic-like effect of serotonin reuptake inhibitors in the elevated T-maze. Behav Brain Res 2003; 147: 185-192.

17. Paxinos G, Watson C. The rat brain in stereotaxic coordinates. Sidney: Academic Press; 1998.

18. Sena LM, Bueno C, Pobbe RL, Andrade TG, Zangrossi $H$ $\mathrm{Jr}$, Viana MB. The dorsal raphe nucleus exerts opposed control on generalized anxiety and panic-related defensive responses in rats. Behav Brain Res 2003; 142: 125-133.

19. Bueno $\mathrm{CH}$, Zangrossi H Jr, Nogueira RL, Soares VP, Viana $M B$. Panicolytic-like effect induced by the stimulation of GABAA and GABAB receptors in the dorsal periaqueductal grey of rats. Eur J Pharmacol 2005; 516: 239-246.

20. Bueno $\mathrm{CH}$, Zangrossi $\mathrm{H} \mathrm{Jr}$, Viana MB. The inactivation of the basolateral nucleus of the rat amygdala has an anxiolytic effect in the elevated T-maze and light/dark transition tests. Braz J Med Biol Res 2005; 38: 1697-1701. 